\title{
Echocardiographic assessment of tricuspid regurgitation and pericardial effusion after cardiac device implantation
}

Katarzyna Wiechecka, Bartosz Wiechecki, Agnieszka Kapłon-Cieślicka, Agata Tymińska, Monika Budnik, Dominika Hołowaty, Krzysztof Jakubowski, Marcin Michalak, Elżbieta Świętoń, Przemysław Stolarz, Roman Steckiewicz, Marcin Grabowski, Piotr Scisło, Janusz Kochanowski, Krzysztof J. Filipiak, Grzegorz Opolski

$1^{\text {st }}$ Chair and Department of Cardiology, Medical University of Warsaw, Poland

\begin{abstract}
Background: The frequency of cardiac implantable electronic device (CIED) implantations is constantly increasing. Pericardial effusion (PE) and tricuspid regurgitation (TR) may occur after CIED implantation. The aim of the present study is to evaluate the prevalence and risk factors for new occurrences or progression of TR and PE early after CIED implantation.

Methods: This is an on-going, single-center, observational study of patients after their first CIED implantation, with an echocardiographic evaluation within 60 days before and 7 days after the procedure. Data are presented for first 110 consecutive patients who underwent CIED implantation from August 2015 to July 2016.

Results: Median age was 75 years, and 44\% were women. In total, 87 (79\%) pacemakers, 21 (19\%) implantable cardioverter-defibrillators and 2 cardiac resynchronization therapy devices were implanted. After CIED implantation, there was TR progression in 17 (16\%) patients: 5 patients developed moderate TR, none developed severe TR. An increase in TR was more often observed after implantations performed by operators in training than by certified operators $(35 \%$ vs. $12 \%, p=0.02)$. New PE after the procedure was observed in $8(7 \%)$ patients and was trivial $(<5 \mathrm{~mm})$ in all cases. Patients with new $P E$ after implantation had lower baseline hemoglobin levels and tended to be women.

Conclusions: New PE and an increase in TR severity are rare complications early after CIED implantation. Operator experience might be related to TR progression. Increasing the number of patients in the current on-going study will allow a more reliable assessment of the prevalence and risk factors of these complications. (Cardiol J 2020; 27, 6: 797-806)
\end{abstract}

Key words: cardiac implantable electronic device, pacemaker, implantable cardioverter-defibrillator, complications

\section{Introduction}

Since the first pacemaker implantation in 1958, the number of cardiac implantable electronic devices (CIEDs): permanent pacemakers (PPMs), implantable cardioverter-defibrillators (ICDs) and cardiac resynchronization therapy (CRT) has been constantly rising [1]. According to a report from the European Heart Rhythm Association, 500,411 PPMs, 85,289 ICDs and 51,274 CRTs were implanted in European Society of Cardiology (ESC) countries in 2013 [2]. Although CIED implanta-

Address for correspondence: Agnieszka Kapłon-Cieślicka, MD, PhD, $1^{\text {st }}$ Chair and Department of Cardiology, Medical University of Warsaw, Public Central Teaching Hospital in Warsaw, ul. Banacha 1a, 02-097 Warszawa, Poland, tel: +48 2259929 58, fax: +48 2259919 57, e-mail: agnieszka.kaplon-cieslicka@wum.edu.pl 
tion is considered a relatively low-risk procedure, especially if performed in specialized centers, it can lead to some early and late complications [3].

Discovering tricuspid valve leaflet perforation at an autopsy in 1974 was the first described case of right ventricle (RV) lead-associated tricuspid regurgitation (TR) [4]. In general, in most cases, TR is secondary to increased pulmonary and RV pressure resulting in RV and tricuspid annular dilatation; less often it is the result of primary leaflet pathology [5]. In the Framingham Heart Study, the prevalence of moderate to severe TR increased with age, reaching up to $1.5 \%$ and $5.6 \%$, respectively, in men and women aged 70 years and more [6]. Due to a lack of prospective studies, the incidence of hemodynamically significant TR after CIED implantation is difficult to estimate, however, in a retrospective, case-control study conducted by Paniagua et al. [7] in a large echocardiography database, the prevalence of moderate to severe TR in patients with transvenous PPM leads was twice as high as in the control group. Depending on time after RV lead implantation, TR can be caused by mechanical interference or lead-related leaflet fibrosis. Mechanical mechanism occurs earlier and includes adherence, impingement of electrodes to tricuspid leaflets or laceration and rarely perforation of valve apparatus, while lead-related fibrosis appears over time after implantation $[8,9]$. The relation between tricuspid leaflets and pacing lead might also be crucial in cases of future transvenous lead extraction, which is a complex surgical procedure itself and might cause or increase TR [10]. TR may also occur as a result of atrioventricular dyssynchrony, specifically in ventricular pacing [11]. To avoid future TR after lead implantation some authors suggest only left ventricular lead stimulation especially in patients with either prosthetic tricuspid valve, annulus or baseline severe TR [12]. Regardless of the mechanism, implantation-induced TR is associated with worse prognosis [13, 14]. However, the exact incidence of implantation-induced TR in a modern series is to be determined, as previous studies usually only included small numbers of patients or were limited by lack of baseline echocardiographic assessment [15-17].

Rarely, CIED implantation procedures may be complicated by pericardial effusion $(\mathrm{PE})$ and tamponade, with a prevalence of approximately $2 \%$ and $0.6 \%$, respectively [18]. These complications can lead to prolonged hospital stay and higher costs $[3,18]$.

The aim of the present study is to evaluate the prevalence and progression of TR and PE early after CIED implantation, and to determine risk factors for the development of these complications. This article presents the design of the current study, as well as preliminary results based on data from the first 110 patients.

\section{Methods}

\section{Study population}

In this single-center, observational, retrospective study, analyses data are presented from 400 consecutive patients after first CIED implantation (PPM, ICD or CRT), who had echocardiographic assessment of TR and PE before and after the procedure. Only patients with echocardiogram performed less than 60 days before and up to 7 days after implantation are included in the study. So far, 110 patients, who underwent device implantation from August 2015 to July 2016, were included in the study.

\section{Data collection}

In the study, data on baseline clinical characteristics, results of diagnostic tests performed, and pharmacotherapy (including antithrombotic treatment) are collected retrospectively from medical records. Data on CIED implantation include: type of device, number of leads, localization of leads, device manufacturer, operator, and information on complications (occurrence or progression of $\mathrm{TR}$, occurrence of PE, pneumothorax, or other complications). Five different physician operators performed the CIEDs implantation: operators 1, 3 and 5 are certified operators with more than 10 years experience in CIED implantation, while operators 2 and 4 were, at the time of the procedure performed, operators in training with experience of less than or equal to 5 years.

\section{Echocardiographic assessment}

All patients included in this study had twodimensional transthoracic echocardiogram performed, before and after the procedure. In the documented department, echocardiographic assessment following CIED implantation is routinely performed within 7 days in all patients, as a standard of care, usually on the first day after the procedure, regardless of the patient's clinical condition. Only patients with available pre- and post-implantation transthoracic echocardiography results with assessment of both PE and TR were included in the study. Echocardiograms are performed in the Department's Echocardiography Laboratory (certified with grade $\mathrm{C}$ accreditation of the Section of Echocardiography of the Polish 


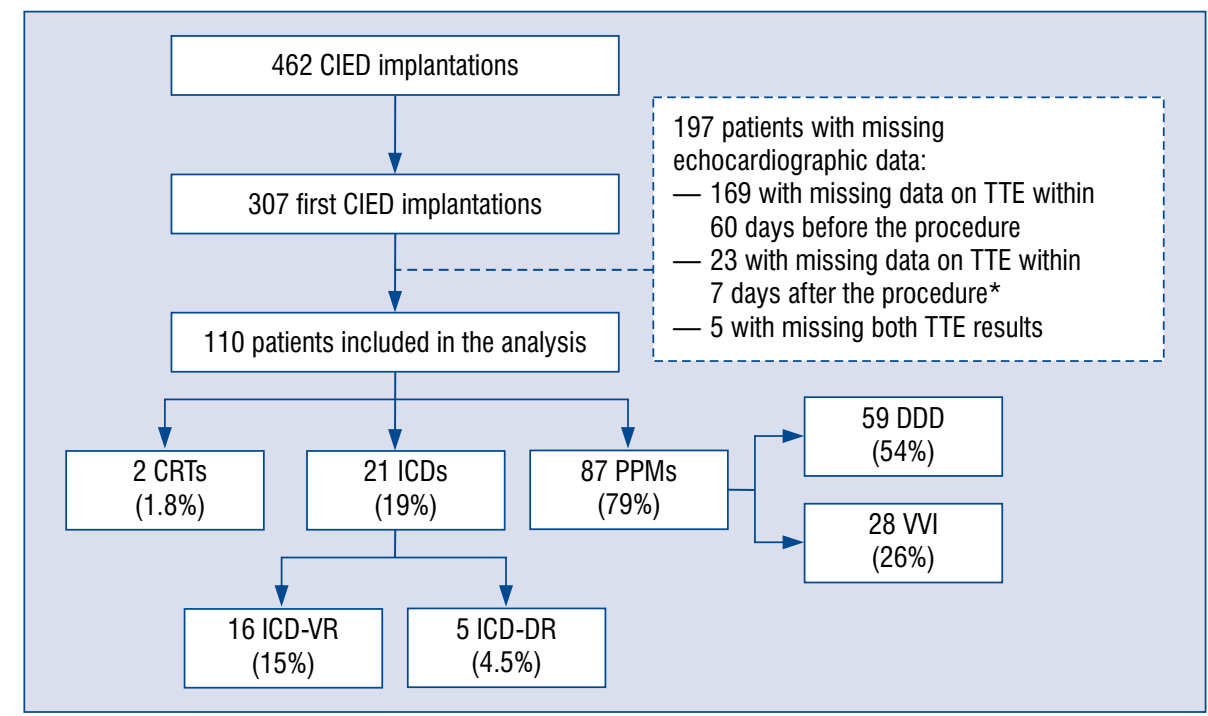

Figure 1. Flow-chart of patient inclusion in the study and types of devices implanted from August 2015 to July 2016 ; ${ }^{*}$ missing data on tricuspid regurgitation after cardiac implantable electronic device (CIED) implantation; CRT — cardiac resynchronization therapy; ICD — implantable cardioverter-defibrillator; ICD-VR — single-chamber cardioverterdefibrillator; ICD-DR - dual-chamber cardioverter-defibrillator; PPM — permanent pacemaker; DDD — dual-chamber pacemaker; VVI — ventricular single-chamber pacemaker; TTE — transthoracic echocardiography.

Cardiac Society), using Philips iE33 or Philips EPIQ 7 Ultrasound Machines (Philips Medical Systems, Andover, Massachusetts, USA) by qualified echocardiographers. Presence of PE and TR severity are analyzed using all standard views, including parasternal, apical and subcostal views. TR is graded as trivial/mild, moderate and severe according to the current European Association of Cardiovascular Imaging (EACVI) guidelines [19]. $\mathrm{PE}$ is graded as trivial $(<5 \mathrm{~mm})$, mild $(\geq 5$ and $<10 \mathrm{~mm}$ ), moderate $(10-20 \mathrm{~mm})$ and large (> $20 \mathrm{~mm}$ ) according to ESC guidelines [20].

In the study, TR is described either as newly developed (if no TR was present before the procedure) or as TR progression 1 ) from trivial $/ \mathrm{mild}$ to moderate, 2) from moderate to severe, 3 ) from trivial/mild to severe, or as a decrease in TR severity. Similarly, PE is reported as newly developed or as an increase in the amount of fluid after the procedure.

\section{Clinical endpoints}

Primary endpoints include: 1) occurrence or progression of TR, and 2) occurrence or progression of $\mathrm{PE}$ after first CIED implantation.

\section{Statistical analysis}

Statistical analyses were performed using SPSS software, version 22 (IBM SPSS Statistics
22, New York, USA). Normally distributed continuous variables were presented as mean values and standard deviations, while ordinal variables and nonnormally distributed continuous variables as median values and interquartile ranges (IQR). Categorical data were presented as percentages. The significance of differences between groups was determined by the Fisher exact test for categorical variables and the Mann-Whitney U test for continuous and ordinal variables respectively. P-value of $\leq 0.05$ was considered significant. All tests were two-tailed.

\section{Results}

From August 2015 to July 2016, 110 patients after their first CIED implantation were included in the study. Figure 1 shows flow-chart of patient inclusion in the study and types of devices implanted. Median age of the study group was 75.1 years and $44 \%$ were female. Hypertension was present in $77 \%$ of patients, coronary artery disease - in $37 \%$, heart failure - in $45 \%$, and atrial fibrillation - in $56 \%$. Table 1 presents baseline clinical characteristics of the study group.

Pre- and post-interventional TR prevalence is shown in Figure 2. Change in TR severity after the procedure was observed in $34(31 \%)$ patients, including $17(16 \%)$ patients with TR worsening and $17(16 \%)$ patients with TR improvement, as 
Table 1. Baseline characteristics of the study population and comparison of patients with and without an increase in tricuspid regurgitation (TR) after cardiac device implantation.

\begin{tabular}{|c|c|c|c|c|}
\hline Variable & $\begin{array}{l}\text { Study population } \\
\qquad(\mathrm{n}=110)\end{array}$ & $\begin{array}{l}\text { With an increase } \\
\text { in } \operatorname{TR}(n=17)\end{array}$ & $\begin{array}{c}\text { Without an } \\
\text { increase in TR } \\
(\mathbf{n}=93)\end{array}$ & $\mathbf{P}$ \\
\hline Age [years] & $75.1(69.0-84.0)$ & $70.0(65.0-84.5)$ & $79.0(69.0-84.0)$ & 0.46 \\
\hline Female gender & $44 \%$ & $59 \%$ & $41 \%$ & 0.19 \\
\hline $\mathrm{BMI}\left[\mathrm{kg} / \mathrm{m}^{2}\right]$ & $\begin{array}{c}27.9(24.1-30.7) \\
\mathrm{n}=91\end{array}$ & $\begin{array}{c}28.1(23.4-29.8) \\
n=11\end{array}$ & $\begin{array}{c}27.7(24.1-30.8) \\
\mathrm{n}=80\end{array}$ & 0.97 \\
\hline \multicolumn{5}{|l|}{ Comorbidities } \\
\hline Hypertension & $77 \%$ & $76 \%$ & $77 \%$ & 1.00 \\
\hline Coronary artery disease & $37 \%$ & $35 \%$ & $38 \%$ & 1.00 \\
\hline Previous MI & $18 \%$ & $12 \%$ & $19 \%$ & 0.73 \\
\hline Prior $\mathrm{PCl}$ & $19 \%$ & $12 \%$ & $20 \%$ & 0.52 \\
\hline Prior CABG & $7.3 \%$ & $0 \%$ & $8.6 \%$ & 0.35 \\
\hline Heart failure & $45 \%$ & $47 \%$ & $44 \%$ & 1.00 \\
\hline Atrial fibrillation: & $56 \%$ & $41 \%$ & $58 \%$ & 0.29 \\
\hline Paroxysmal & $29 \%$ & $24 \%$ & $30 \%$ & 0.77 \\
\hline Persistent & $5.5 \%$ & $5.9 \%$ & $5.4 \%$ & 1.00 \\
\hline Permanent & $21 \%$ & $12 \%$ & $23 \%$ & 0.52 \\
\hline Diabetes & $26 \%$ & $18 \%$ & $27 \%$ & 0.55 \\
\hline Obesity & $32 \%$ & $27 \%$ & $33 \%$ & 0.56 \\
\hline Hyperlipidemia & $67 \%$ & $82 \%$ & $65 \%$ & 0.26 \\
\hline Current or former smoking & $33 \%$ & $29 \%$ & $33 \%$ & 1.00 \\
\hline \multicolumn{5}{|l|}{ Pharmacotherapy } \\
\hline Anticoagulation: & $67 \%$ & $53 \%$ & $70 \%$ & 0.17 \\
\hline Rivaroxaban & $20 \%$ & $30 \%$ & $18 \%$ & 0.50 \\
\hline Dabigatran & $6.4 \%$ & $0 \%$ & $7.5 \%$ & 0.59 \\
\hline Vitamin $\mathrm{K}$ antagonist & $19 \%$ & $12 \%$ & $20 \%$ & 0.50 \\
\hline LMWH as bridging therapy & $31 \%$ & $24 \%$ & $33 \%$ & 0.38 \\
\hline Single antiplatelet therapy & $26 \%$ & $18 \%$ & $27 \%$ & 0.55 \\
\hline Dual antiplatelet therapy & $3.6 \%$ & $5.9 \%$ & $3.2 \%$ & 0.49 \\
\hline Diuretics & $73 \%$ & $65 \%$ & $75 \%$ & 0.38 \\
\hline \multicolumn{5}{|l|}{ Laboratory findings } \\
\hline Hemoglobin $[\mathrm{g} / \mathrm{dL}]$ & $13.0(12.0-14.0)$ & $13.0(12.0-14.4)$ & $13.0(12.0-14.0)$ & 0.97 \\
\hline WBC count $\left[10^{3} / \mathrm{mm}^{3}\right]$ & $7.1(5.9-8.5)$ & $6.5(5.7-8.6)$ & $7.2(5.9-8.6)$ & 0.60 \\
\hline Platelets $\left[10^{3} / \mathrm{mm}^{3}\right]$ & $205(156-243)$ & $223(193-243)$ & $202(149-245)$ & 0.14 \\
\hline Serum creatinine $[\mathrm{mg} / \mathrm{dL}]$ & $1.12(0.91-1.36)$ & $0.96(0.87-1.20)$ & $1.17(0.92-1.39)$ & 0.21 \\
\hline eGFR $\left[\mathrm{mL} / \mathrm{min} / 1.73 \mathrm{~m}^{2}\right]$ & $56(45-60)$ & $60(44-60)$ & $55(45-60)$ & 0.32 \\
\hline $\mathrm{CRP}[\mathrm{mg} / \mathrm{L}]$ & $\begin{array}{c}2.35(1.3-7.0) \\
n=100\end{array}$ & $\begin{array}{c}3.1(1.3-7.2) \\
n=15\end{array}$ & $\begin{array}{c}2.2(1.2-5.6) \\
n=85\end{array}$ & 0.50 \\
\hline NT-proBNP [pg/mL] & $\begin{array}{c}1123(482-2313) \\
n=78\end{array}$ & $\begin{array}{c}1464(523-2646) \\
n=13\end{array}$ & $\begin{array}{c}991(464-2238) \\
n=65\end{array}$ & 0.62 \\
\hline INR & $\begin{array}{c}1.1(1.0-1.2) \\
n=104\end{array}$ & $\begin{array}{c}1.1(1.0-1.1) \\
\mathrm{n}=15\end{array}$ & $\begin{array}{c}1.1(1.0-1.2) \\
n=89\end{array}$ & 0.72 \\
\hline APTT [s] & $\begin{array}{c}30.9(27.4-35.8) \\
n=98\end{array}$ & $\begin{array}{c}31.5(28.0-36.8) \\
n=14\end{array}$ & $\begin{array}{c}30.9(27.2-35.6) \\
n=84\end{array}$ & 0.68 \\
\hline
\end{tabular}

APTT — activated partial thromboplastin time; BMI — body mass index; CABG — coronary artery bypass grafting; CRP — C-reactive protein; eGFR - estimated glomerular filtration rate; INR — international normalized ratio; LMWH — low-molecular weight heparin; MI — myocardial infarction; NT-proBNP - N-terminal pro-B-type natriuretic peptide; $\mathrm{PCl}$ - percutaneous coronary intervention; PT — prothrombin time: WBC - white blood cell 


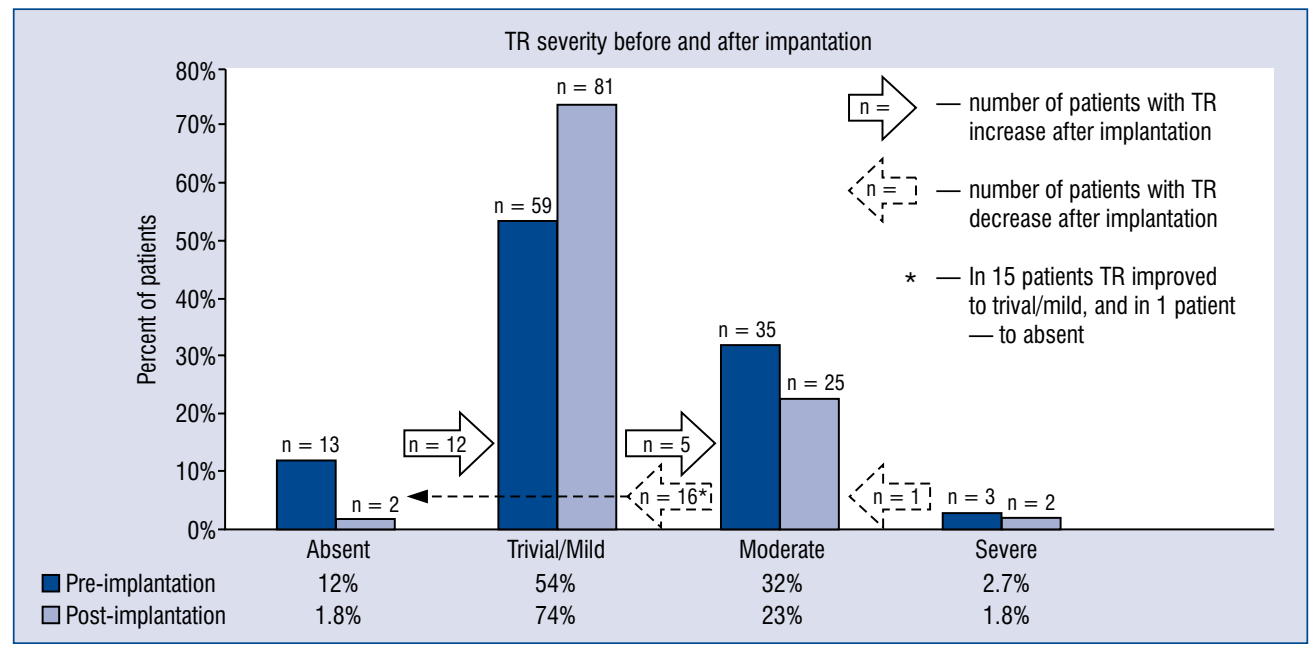

Figure 2. Pre- and post-interventional prevalence of tricuspid regurgitation (TR) in the study group.

presented in Figure 2. Comparison of patients with and without an increase in TR after the procedure is presented in Tables 1 and 2 . In the present study, newly developed TR and/or TR progression was more often observed after implantations performed by operators in training than after procedures executed by certified operators ( $35 \%$ vs. $12 \%, \mathrm{p}=0.02$ ), as shown in Table 3.

None of the patients had any PE before the procedure. $\mathrm{PE}$ after the procedure was observed in 8 of 110 patients $(7.3 \%)$ and only trivial $(<5 \mathrm{~mm})$ amounts were found. Comparisons of patients with and without PE after the procedure is shown in Tables 4 and 5. Patients who developed PE after CIED implantation had lower baseline hemoglobin concentration. There was a tendency for women to develop PE more often.

No cases of pneumothorax nor other severe complications were observed early after CIED implantation in the study group.

\section{Discussion}

The preliminary results of the current study suggest that newly developed TR or worsening of TR early after CIED implantation was not very common (16\% of patients) and was, in most cases, not hemodynamically significant (at least initially), as none of the patients developed severe TR and only $5(4.5 \%)$ patients developed moderate TR. However, these observations were made early after CIED implantation, and it is difficult to predict further TR progression and its implications in long-term follow-up in these patients. Previous studies did not yield consistent results, mostly because they were retrospective analyses conducted in small patient cohorts, allowing only a rough estimation of post-implantation TR incidence. The present findings are similar to the results of a study by Rothschild et al. [15] on small population $(\mathrm{n}=36)$, where $6(17 \%)$ patients developed an immediate increase in TR grade post-implantation, nevertheless, there was no progression to moderate or severe TR in any of the patients. However, after a median of 113 days, Klutstein et al. [21] reported worsening of TR by more than 2 grades in $18 \%$ of patients with pre-procedural TR described as less than moderate. On the contrary, Webster et al. [22] studied a population of 123 patients at a median age of 16 years at the time of RV-lead placement, and reported no TR worsening 8 months after implantation and only modest TR increase (from 1.54 to 1.69 on a scale from 0 to 4 ) after over 2 years. The discrepancy in results between studies may be partially explained by different time frames of post-procedure TR evaluation, as mechanical component of lead-related TR worsening appears earlier than fibrosis and scarring of valve apparatus. In the present study, prevalence of new TR development/TR progression in patients after procedure differed between the operators and was higher after implantation performed by those less experienced. These findings suggest that the experience of the operator may have significant impact on developing TR regurgitation after the procedure.

Another risk factor for CIED-related TR might be the number of implanted leads. Postaci 
Table 2. Comparison of patients with and without an increase in tricuspid regurgitation (TR) after cardiac device implantation - procedure-related variables.

\begin{tabular}{|c|c|c|c|}
\hline Variable & $\begin{array}{l}\text { With an increase in TR } \\
\qquad(\mathrm{n}=17)\end{array}$ & $\begin{array}{l}\text { Without an increase in TR } \\
\qquad(\mathrm{n}=93)\end{array}$ & $\mathbf{P}$ \\
\hline \multicolumn{4}{|l|}{ Cardiac device type } \\
\hline DDD & $71 \% ; 12 / 17$ & $51 \% ; 47 / 93$ & 0.19 \\
\hline VVI & $12 \% ; 2 / 17$ & $28 \% ; 26 / 93$ & 0.23 \\
\hline ICD & $18 \% ; 3 / 17$ & $19 \% ; 18 / 93$ & 1.00 \\
\hline CRT & $0 \% ; 0 / 17$ & $2.2 \% ; 2 / 93$ & 1.00 \\
\hline \multicolumn{4}{|l|}{ Number of leads } \\
\hline 1 & $29 \% ; 5 / 17$ & $42 \% ; 39 / 93$ & 0.42 \\
\hline 2 & $71 \% ; 12 / 17$ & $56 \% ; 52 / 93$ & 0.30 \\
\hline 3 & $0 \% ; 0 / 17$ & $2.2 \% ; 2 / 93$ & 1.00 \\
\hline \multicolumn{4}{|l|}{ Type/localization of lead } \\
\hline Atrial & $71 \% ; 12 / 17$ & $58 \% ; 54 / 93$ & 0.42 \\
\hline Ventricular for stimulation & $82 \% ; 14 / 17$ & $79 \% ; 73 / 93$ & 1.00 \\
\hline Ventricular for defibrillation & $18 \% ; 3 / 17$ & $22 \% ; 20 / 93$ & 1.00 \\
\hline \multicolumn{4}{|l|}{ Manufacturer } \\
\hline Biotronik & $65 \% ; 11 / 17$ & $51 \% ; 47 / 93$ & 0.50 \\
\hline Medtronic & $35 \% ; 6 / 17$ & $32 \% ; 30 / 93$ & 0.80 \\
\hline St. Jude Medical & $0 \% ; 0 / 17$ & $17 \% ; 16 / 93$ & 0.13 \\
\hline Operator & & & 0.051 \\
\hline Operator no. 1 & $0 \% ; 0 / 13^{*}$ & $100 \% ; 13 / 13^{*}$ & \\
\hline Operator no. 2 & $27 \% ; 3 / 11 *$ & $73 \% ; 8 / 11 *$ & \\
\hline Operator no. 3 & $11 \% ; 3 / 27^{*}$ & $89 \% ; 24 / 27^{*}$ & \\
\hline Operator no. 4 & $50 \% ; 3 / 6^{*}$ & $50 \% ; 3 / 6^{*}$ & \\
\hline Operator no. 5 & $15 \% ; 8 / 53^{*}$ & $85 \% ; 45 / 53^{*}$ & \\
\hline
\end{tabular}

*Refers to the number of procedures performed by the given operator; DDD — dual-chamber pacemaker; CRT — cardiac resynchronization therapy; ICD — implantable cardioverter defibrillator; VVI — ventricular single-chamber pacemaker

Table 3. Changes in tricuspid regurgitation (TR) severity after procedures performed by certified operators and operators in training.

\begin{tabular}{lccc}
\hline $\begin{array}{l}\text { Post-procedural } \\
\text { changes in TR }\end{array}$ & $\begin{array}{c}\text { Certified operators* } \\
\text { (93 procedures) }\end{array}$ & $\begin{array}{c}\text { Operators in training** } \\
\text { (17 procedures) }\end{array}$ & P \\
\hline Increase in TR & $12 \% ; 11 / 93$ & $35 \% ; 6 / 17$ & $\mathbf{0 . 0 2}$ \\
No change in TR & $70 \% ; 65 / 93$ & $65 \% ; 11 / 17$ & 0.78 \\
Decrease in TR & $18 \% ; 17 / 93$ & $0 \% ; 0 / 17$ & 0.07 \\
\hline
\end{tabular}

*Operators 1, 3, and 5; **operators 2 and 4

et al. [23] observed that $9 \%$ of 32 patients with one ventricular lead and $56 \%$ of 18 patients with two ventricular leads developed severe TR. In the current study, only the first CIED implantations are analyzed, and thus the study does not include patients with previously implanted ventricular leads in whom a second ventricular lead (e.g. defibrillation lead) is placed. Al-Bawardy et al. [24] studied a group of 1596 patients who underwent CIED implantation, with a median follow-up of 10 months. Most patients (61\%) had 2 leads implanted, $20 \%$ had 3 leads implanted. The authors concluded that the type of cardiac device is not related to TR worsening. In contrast, Kim et al. [25] reported that TR worsening was more common after ICD than PPM implantation (32\% vs. $21 \%, \mathrm{p}=0.048)$. In the present study, ICD implantation was not associated with elevated risk for TR worsening. Increasing the number of patients in the current study would have al- 
Table 4. Comparison of patients with and without pericardial effusion after cardiac device implantation — clinical and laboratory variables.

\begin{tabular}{|c|c|c|c|}
\hline Variable & $\begin{array}{l}\text { With pericardial effusion } \\
\qquad(\mathrm{n}=8)\end{array}$ & $\begin{array}{l}\text { Without pericardial effusion } \\
\qquad(\mathrm{n}=102)\end{array}$ & $\mathbf{P}$ \\
\hline Age [years] & $77.5(68.0-83.0)$ & $78.5(68.8-84.0)$ & 0.96 \\
\hline Female gender & $75 \%$ & $41 \%$ & 0.08 \\
\hline BMI $\left[\mathrm{kg} / \mathrm{m}^{2}\right]$ & $26.1(24.8-34.1) ; n=7$ & $28.0(24.0-30.8) ; \mathrm{n}=84$ & 0.94 \\
\hline \multicolumn{4}{|l|}{ Comorbidities } \\
\hline Hypertension & $75 \%$ & $78 \%$ & 1.00 \\
\hline Coronary artery disease & $63 \%$ & $35 \%$ & 0.12 \\
\hline Previous MI & $25 \%$ & $18 \%$ & 0.64 \\
\hline Prior PCl & $25 \%$ & $19 \%$ & 0.65 \\
\hline Prior CABG & $13 \%$ & $6.9 \%$ & 0.47 \\
\hline Heart failure & $25 \%$ & $46 \%$ & 0.30 \\
\hline Atrial fibrillation: & $50 \%$ & $56 \%$ & 1.00 \\
\hline Paroxysmal & $38 \%$ & $28 \%$ & 0.69 \\
\hline Persistent & $13 \%$ & $4.9 \%$ & 0.37 \\
\hline Permanent & $0 \%$ & $23 \%$ & 0.20 \\
\hline Diabetes & $13 \%$ & $27 \%$ & 0.68 \\
\hline Obesity & $13 \%$ & $33 \%$ & 0.42 \\
\hline Hyperlipidemia & $75 \%$ & $67 \%$ & 1.00 \\
\hline Current or former smoking & $25 \%$ & $33 \%$ & 1.00 \\
\hline \multicolumn{4}{|l|}{ Pharmacotherapy } \\
\hline Anticoagulation: & $63 \%$ & $68 \%$ & 1.00 \\
\hline Rivaroxaban & $25 \%$ & $20 \%$ & 0.60 \\
\hline Dabigatran & $13 \%$ & $5.9 \%$ & 0.36 \\
\hline Vitamin $\mathrm{K}$ antagonist & $13 \%$ & $20 \%$ & 1.00 \\
\hline LMWH as bridging therapy & $13 \%$ & $33 \%$ & 0.64 \\
\hline Single antiplatelet therapy & $25 \%$ & $26 \%$ & 1.00 \\
\hline Dual antiplatelet therapy & $13 \%$ & $2.9 \%$ & 0.26 \\
\hline Diuretics & $75 \%$ & $73 \%$ & 1.00 \\
\hline \multicolumn{4}{|l|}{ Laboratory findings } \\
\hline Hemoglobin $[\mathrm{g} / \mathrm{dL}]$ & $12.0(11.7-12.8)$ & $13.0(12.1-14.1)$ & 0.04 \\
\hline WBC count $\left[10^{3} / \mathrm{mm}^{3}\right]$ & $8.3(6.3-10.1)$ & $7.0(5.9-8.3)$ & 0.13 \\
\hline Platelets $\left[10^{3} / \mathrm{mm}^{3}\right]$ & $219(169-272)$ & $204(151-243)$ & 0.38 \\
\hline Serum creatinine $[\mathrm{mg} / \mathrm{dL}]$ & $1.17(0.74-1.28)$ & $1.10(0.91-1.38)$ & 0.53 \\
\hline eGFR [mL/min/1.73 m²] & $52(45-60)$ & $57(44-60)$ & 0.80 \\
\hline CRP [mg/L] & $5.6(1.2-12.5)$ & $2.3(1.3-5.5) ; n=92$ & 0.34 \\
\hline NT-proBNP [pg/mL] & $774(430-5104) ; n=7$ & $1187(559-2240) ; n=71$ & 0.97 \\
\hline INR & $1.0(0.99-1.1)$ & $1.1(1.0-1.2) ; n=96$ & 0.36 \\
\hline APTT [s] & $30.4(27.3-35.3) ; n=7$ & $31.0(27.4-35.9) ; \mathrm{n}=90$ & 0.86 \\
\hline
\end{tabular}

APTT — activated partial thromboplastin time; BMI - body mass index; CABG - coronary artery bypass grafting; CRP — C-reactive protein; eGFR — estimated glomerular filtration rate; INR — international normalized ratio LMWH — low-molecular weight heparin; MI — myocardial infarction; NT-proBNP - N-terminal pro-B-type natriuretic peptide; $\mathrm{PCl}$ - percutaneous coronary intervention; PT - prothrombin time; WBC — white blood cell

lowed establishing whether the number and type of implanted leads is related to the risk of TR development or worsening.
Some data suggest that the technique of echocardiographic evaluation of post-procedural TR may also affect the results. In one retrospective 
Table 5. Comparison of patients with and without pericardial effusion after cardiac device implantation - procedure-related variables.

\begin{tabular}{|c|c|c|c|}
\hline Variable & $\begin{array}{l}\text { With pericardial effusion } \\
\qquad(n=8)\end{array}$ & $\begin{array}{l}\text { Without pericardial effusion } \\
\qquad(\mathrm{n}=102)\end{array}$ & $\mathbf{P}$ \\
\hline \multicolumn{4}{|l|}{ Cardiac device type } \\
\hline DDD & $63 \% ; 5 / 8$ & $53 \% ; 54 / 102$ & 0.72 \\
\hline VVI & $25 \% ; 2 / 8$ & $26 \% ; 26 / 102$ & 1.00 \\
\hline ICD & $13 \% ; 1 / 8$ & $20 \% ; 20 / 102$ & 1.00 \\
\hline CRT & $0 \% ; 0 / 8$ & $2.0 \% ; 2 / 102$ & 1.00 \\
\hline \multicolumn{4}{|l|}{ Number of leads } \\
\hline 1 & $25 \% ; 2 / 8$ & $42 \% ; 42 / 102$ & 0.47 \\
\hline 2 & $75 \% ; 6 / 8$ & $57 \% ; 58 / 102$ & 0.46 \\
\hline 3 & $0 \% ; 0 / 8$ & $2.0 \% ; 2 / 102$ & 1.00 \\
\hline \multicolumn{4}{|l|}{ Type/localization of lead } \\
\hline Atrial & $75 \% ; 6 / 8$ & $59 \% ; 60 / 102$ & 0.47 \\
\hline Ventricular for stimulation & $88 \% ; 7 / 8$ & $78 \% ; 80 / 102$ & 0.70 \\
\hline Ventricular for defibrillation & $13 \% ; 1 / 8$ & $22 \% ; 22 / 102$ & 0.70 \\
\hline \multicolumn{4}{|l|}{ Manufacturer } \\
\hline Biotronik & $63 \% ; 5 / 8$ & $52 \% ; 53 / 102$ & 0.70 \\
\hline Medtronic & $13 \% ; 1 / 8$ & $34 \% ; 35 / 102$ & 0.27 \\
\hline St. Jude Medical & $25 \% ; 2 / 8$ & $14 \% ; 14 / 102$ & 0.35 \\
\hline Operator & & & 0.52 \\
\hline Operator no. 1 & $0 \% ; 0 / 13^{*}$ & $100 \% ; 13 / 13^{*}$ & \\
\hline Operator no. 2 & $0 \% ; 0 / 11^{*}$ & $100 \% ; 11 / 11^{*}$ & \\
\hline Operator no. 3 & $11 \% ; 3 / 27^{*}$ & $89 \% ; 24 / 27 *$ & \\
\hline Operator no. 4 & $17 \% ; 1 / 6^{*}$ & $83 \% ; 5 / 6^{*}$ & \\
\hline Operator no. 5 & $7.5 \% ; 4 / 53^{*}$ & $93 \% ; 49 / 53^{*}$ & \\
\hline
\end{tabular}

*Refers to the number of procedures performed by the given operator; DDD — dual-chamber pacemaker; CRT — cardiac resynchronization therapy; ICD - implantable cardioverter defibrillator; VVI — ventricular single-chamber pacemaker

study, transthoracic compared to transesophageal echocardiography detected fewer lead-related TRs in patients after CIED implantation ( $22 \%$ vs. $45 \%)$ [26]. The importance of reliable TR diagnosis is related to unfavorable impact of hemodynamically significant TR on prognosis, which results predominantly from its deleterious effects on RV dimensions and function. Other important clinical implications of significant TR include occurrence of rhythm disturbances such as atrial fibrillation and the need for chronic anticoagulation [27, 28].

In the present study, there was also a proportion of patients with a decrease in TR severity after CIED implantation. This might be related to possible volume depletion in these patients (fasting before the procedure, possibly more intensive diuretic treatment), as functional TR is a dynamic disease, changing in response to variation in preload and afterload. Another possible explanation might be that echocardiographic visualization is usually impaired for a few days after CIED implantation due to edema of the subcutaneous tissue in left subclavicular region and the diminished range of left upper limb movement, which might result in an underestimation of the actual TR volume. Furthermore, lead-induced artifacts might have impaired proper assessment of TR.

Herein, consistent with previous publications, new post-implantation $\mathrm{PE}$ was a rare complication [18]. A trend towards higher risk of post-procedural $\mathrm{PE}$ in women was observed, which is in line with a study by Ohlow et al. [18], in which female gender was associated with a higher incidence of any PE. The authors suggested this may be due to a thinner RV wall in women, related to a reduced extension of ventricular hypotrophy and lower RV pressure in women, as shown in population-based studies [21, 27]. Thinner RV walls could increase the risk of ventricular perforation in women [18]. In the same study by Ohlow et al. [18], patients 
developing PE after CIED implantation were more often on antiplatelet therapy than patients without $\mathrm{PE}$ after intervention. Tompkins et al. [29] demonstrated that bleeding risk is significantly higher for patients on dual antiplatelet therapy undergoing PPM or ICD implantation and slightly higher for patients receiving acetylsalicylic acid alone. In the present study, patients with post-procedural $\mathrm{PE}$ more often received dual antiplatelet therapy than patients without this complication, although this difference did not reach statistical significance. There was no significant difference in the prevalence of post-procedural PE between patients with and without single antiplatelet or anticoagulant treatment, however, this might be related to a relatively small sample size. Still, patients with $\mathrm{PE}$ had lower hemoglobin concentration at baseline. In several previous studies, low hemoglobin concentration proved an independent predictor of bleeding, including bleeding complications after cardiac procedures [30, 31]. Importantly, in patients who did develop PE after implantation, only a trivial amount of fluid was observed, with no clinical consequences.

\section{Limitations of the study}

The present study has several limitations. First, it is a single-center study, including (thus far) a relatively small cohort of patients. However, the final number of patients in the study will exceed 400. Secondly, as presented in Figure 1, a large number of patients after first CIED implantation were not eligible for inclusion, mainly due to missing data on pre-implantation echocardiogram. Thirdly, echocardiographic assessment is limited to the early post-implantation period, without longterm follow-up. Lastly, this study is a retrospective analysis of medical records, and thus, allows only an approximate estimation of new post-implantation TR and PE incidence.

\section{Conclusions}

Preliminary data suggests that CIED implantation may lead to early development or progression of TR in approximately $16 \%$ of patients, however, in most of them TR was not hemodynamically significant. It seems that operator experience might be an important risk factor for TR development. PE occurred rarely after CIED implantation, and was, in all cases, trivial and lead to no clinical sequel. Increasing the number of patients in the on-going study will enable a more reliable assessment of the prevalence and the risk factors of those CIED implantation-related complications. Still, the most appropriate method to evaluate the true incidence of those complications would be to conduct a prospective study.

Conflict of interest: Marcin Michalak received educational grants from Biotronik, Medtronic, St. Jude Medical, and speaking fee from Biotronik outside the submitted work. Marcin Grabowski received speaking/consulting fees from Abbott/St. Jude Medical, Biotronik, Medtronic — outside the submitted work. Other authors report no conflicts of interest.

\section{References}

1. Aquilina O. A brief history of cardiac pacing. Images Paediatr Cardiol. 2006; 8(2): 17-81, indexed in Pubmed: 22368662.

2. Raatikainen MJ, Arnar DO, Zeppenfeld K, et al. Statistics on the use of cardiac electronic devices and electrophysiological procedures in the European Society of Cardiology countries: 2014 report from the European Heart Rhythm Association. Europace. 2015; 17 Suppl 1: i1-75, doi: 10.1093/europace/euu300, indexed in Pubmed: 25616426.

3. Brignole M, Auricchio A, Baron-Esquivias G, et al. 2013 ESC guidelines on cardiac pacing and cardiac resynchronization therapy: the task force on cardiac pacing and resynchronization therapy of the European Society of Cardiology (ESC). Developed in collaboration with the European Heart Rhythm Association (EHRA). Europace. 2013; 15(8): 1070-1118, doi: 10.1093/europace/eut206, indexed in Pubmed: 23801827.

4. Gould L, Reddy CV, Yacob U, et al. Perforation of the tricuspid valve by a transvenous pacemaker. JAMA. 1974; 230(1): 86-87, indexed in Pubmed: 4479257.

5. Agarwal S, Tuzcu EM, Rodriguez ER, et al. Interventional cardiology perspective of functional tricuspid regurgitation. Circ Cardiovasc Interv. 2009; 2(6): 565-573, doi: 10.1161/CIRCINTERVENTIONS.109.878983, indexed in Pubmed: 20031775.

6. Singh JP, Evans JC, Levy D, et al. Prevalence and clinical determinants of mitral, tricuspid, and aortic regurgitation (the Framingham Heart Study). Am J Cardiol. 1999; 83(6): 897-902, indexed in Pubmed: 10190406.

7. Paniagua D, Aldrich HR, Lieberman EH, et al. Increased prevalence of significant tricuspid regurgitation in patients with transvenous pacemakers leads. Am J Cardiol. 1998; 82(9): 1130-2, A9, indexed in Pubmed: 9817497.

8. Al-Bawardy R, Krishnaswamy A, Bhargava M, et al. Tricuspid regurgitation in patients with pacemakers and implantable cardiac defibrillators: a comprehensive review. Clin Cardiol. 2013; 36(5): 249-254, doi: 10.1002/clc.22104, indexed in Pubmed: 23529935.

9. Champagne J, Poirier P, Dumesnil JG, et al. Permanent pacemaker lead entrapment: role of the transesophageal echocardiography. Pacing Clin Electrophysiol. 2002; 25(7): 1131-1134, indexed in Pubmed: 12164456.

10. Gawalko M, Kołodzińska A, Grabowski M, et al. Transvenous lead removal with a fragment of a papillary muscle - a silent complication. Heart Beat J. 2017; 1: 41-42, doi: 10.24255/hbj/68144.

11. Roeffel S, Bracke F, Meijer A, et al. Transesophageal echocardiographic evaluation of tricuspid valve regurgitation during pace- 
maker and implantable cardioverter defibrillator lead extraction. Pacing Clin Electrophysiol. 2002; 25(11): 1583-1586, indexed in Pubmed: 12494615.

12. Zawadzki J, Januszkiewicz Ł, Cacko A, et al. Left Ventricular Pacing via Coronary Sinus in a Patient With a Mechanical Tricuspid Valve. Heart Beat J. 2017; 2: 36-37, doi: 10.24255/hbj/81266.

13. Nath J, Foster E, Heidenreich PA. Impact of tricuspid regurgitation on long-term survival. J Am Coll Cardiol. 2004; 43(3): 405-409, doi: 10.1016/j.jacc.2003.09.036, indexed in Pubmed: 15013122.

14. Höke U, Auger D, Thijssen J, et al. Significant lead-induced tricuspid regurgitation is associated with poor prognosis at longterm follow-up. Heart. 2014; 100(12): 960-968, doi: 10.1136/ heartjnl-2013-304673, indexed in Pubmed: 24449717.

15. Rothschild DP, Goldstein JA, Kerner N, et al. Pacemaker-induced tricuspid regurgitation is uncommon immediately postimplantation. J Interv Card Electrophysiol. 2017; 49(3): 281-287, doi: 10.1007/s10840-017-0266-2, indexed in Pubmed: 28685199.

16. Arabi P, Özer N, Ateş AH, et al. Effects of pacemaker and implantable cardioverter defibrillator electrodes on tricuspid regurgitation and right sided heart functions. Cardiol J. 2015; 22(6): 637-644, doi: 10.5603/CJ.a2015.0060, indexed in Pubmed: 26412607.

17. Fanari $Z$, Hammami S, Hammami MB, et al. The effects of right ventricular apical pacing frequency on left ventricle function and pulmonary artery pressure. Del Med J. 2015; 87(8): 244-247, indexed in Pubmed: 26402927.

18. Ohlow MA, Lauer B, Brunelli M, et al. Incidence and predictors of pericardial effusion after permanent heart rhythm device implantation: prospective evaluation of 968 consecutive patients. Circ J. 2013; 77(4): 975-981, indexed in Pubmed: 23269085.

19. Lancellotti P, Tribouilloy C, Hagendorff A, et al. Recommendations for the echocardiographic assessment of native valvular regurgitation: an executive summary from the European Association of Cardiovascular Imaging. Eur Heart J Cardiovasc Imaging. 2013; 14(7): 611-644, doi: 10.1093/ehjci/jet105, indexed in Pubmed: 23733442.

20. Adler Y, Charron P, Imazio M, et al. 2015 ESC Guidelines for the diagnosis and management of pericardial diseases: The Task Force for the Diagnosis and Management of Pericardial Diseases of the European Society of Cardiology (ESC)Endorsed by: The European Association for Cardio-Thoracic Surgery (EACTS). Eur Heart J. 2015; 36(42): 2921-2964, doi: 10.1093/eurheartj/ ehv318, indexed in Pubmed: 26320112.

21. Klutstein M, Balkin J, Butnaru A, et al. Tricuspid incompetence following permanent pacemaker implantation. Pacing Clin Elec- trophysiol. 2009; 32 Suppl 1: S135-S137, doi: 10.1111/j.15408159.2008.02269.x, indexed in Pubmed: 19250077.

22. Webster G, Margossian R, Alexander ME, et al. Impact of transvenous ventricular pacing leads on tricuspid regurgitation in pediatric and congenital heart disease patients. J Interv Card Electrophysiol. 2008; 21(1): 65-68, doi: 10.1007/s10840-0079183-0, indexed in Pubmed: 18040765.

23. Postaci N, Ekşi K, Bayata S, et al. Effect of the number of ventricular leads on right ventricular hemodynamics in patients with permanent pacemaker. Angiology. 1995; 46(5): 421-424, doi: 10.1 177/000331979504600509, indexed in Pubmed: 7741326.

24. Al-Bawardy R, Krishnaswamy A, Rajeswaran J, et al. Tricuspid regurgitation and implantable devices. Pacing Clin Electrophysiol. 2015; 38(2): 259-266, doi: 10.1111/pace.12530, indexed in Pubmed: 25377489.

25. Kim JB, Spevack DM, Tunick PA, et al. The effect of transvenous pacemaker and implantable cardioverter defibrillator lead placement on tricuspid valve function: an observational study. J Am Soc Echocardiogr. 2008; 21(3): 284-287, doi: 10.1016/j. echo.2007.05.022, indexed in Pubmed: 17604958.

26. Lin G, Nishimura RA, Connolly HM, et al. Severe symptomatic tricuspid valve regurgitation due to permanent pacemaker or implantable cardioverter-defibrillator leads. J Am Coll Cardiol. 2005; 45(10): 1672-1675, doi: 10.1016/j.jacc.2005.02.037, indexed in Pubmed: 15893186.

27. Michniewicz E, Mlodawska E, Lopatowska P, et al. Patients with atrial fibrillation and coronary artery disease - Double trouble. Adv Med Sci. 2018; 63(1): 30-35, doi: 10.1016/j.advms.2017.06.005, indexed in Pubmed: 28818746.

28. Tomaszuk-Kazberuk A, Kołtowski L, Balsam P, et al. Use of non-vitamin $\mathrm{K}$ antagonist oral anticoagulants (NOACs) in patients with atrial fibrillation - Messages from the 2018 EHRA. Cardiol J. 2018; 25(4): 423-440, doi: 10.5603/CJ.2018.0080, indexed in Pubmed: 30211927.

29. Tompkins C, Cheng A, Dalal D, et al. Dual antiplatelet therapy and heparin "bridging" significantly increase the risk of bleeding complications after pacemaker or implantable cardioverter-defibrillator device implantation. J Am Coll Cardiol. 2010; 55(21): 2376-2382, doi: 10.1016/j.jacc.2009.12.056, indexed in Pubmed: 20488310.

30. Tettey M, Aniteye E, Sereboe L, et al. Predictors of post operative bleeding and blood transfusion in cardiac surgery. Ghana Med J. 2009; 43(2): 71-76, indexed in Pubmed: 21326845.

31. Kalra PR, Greenlaw N, Ferrari R, et al. Hemoglobin and change in hemoglobin status predict mortality, cardiovascular events, and bleeding in stable coronary artery disease. Am J Med. 2017; 130(6): 720-730, doi: 10.1016/j.amjmed.2017.01.002, indexed in Pubmed: 28109968. 